\title{
En torno a la imaginación en Martha Nussbaum y Kant
}

\author{
Imagination in Martha Nussbaum and Kant
}

Miguel Herszenbaun*

\begin{abstract}
Resumen: En Justicia poética, Martha Nussbaum pone a la imaginación del lector de novelas en un lugar destacado, convirtiéndola en un elemento central de la decisión judicial. En el presente trabajo, me propongo defender la tesis de que la propuesta de Nussbaum es en parte de raigambre kantiana. Sin embargo, en el análisis pormenorizado de la función de la imaginación en Kant y Nussbaum, se advertirán los matices que trazan la separación entre lo que comparten y lo que los diferencia. En dicho análisis, defenderé que el problema general que viene a resolver la imaginación concebida por Nussbaum es la articulación entre lo singular y lo universal a través de una facultad capaz de desarrollarse y vincularse con lo emocional (aunque no reducida simplemente a la emoción).
\end{abstract}

Palabras clave: Nussbaum, Kant, Imaginación, Literatura, Derecho

Abstract: In her book Poetic Justice, Martha Nussbaum supports the thesis that the imagination plays a major role in the judicial decision-making. In this paper, I intend to defend that Nussbaum's thesis is partially Kantian. However, by analyzing in detail how the imagination works in Kant and in Nussbaum, I will be able to show the main differences and similarities. I claim that the main problem that Nussbaum's imagination is thought to solve is the articulation between singular and universal. This is done by means of a faculty capable of connecting with the emotional aspect of the human being.

* Doctor en filosofía (UBA), profesor de filosofía (UBA) y abogado (UBA). Investigador del CONICET. Docente regular del Departamento de Filosofía del Derecho (Facultad de Derecho, UBA), docente de la especialización en Derecho Penal (Facultad de Derecho, UBA) y docente de "Historia de la filosofía moderna" (Facultad de Filosofía y Letras, UBA). Miembro del Grupo de Estudios Kantianos (UBA), Grupo de Estudios Hegelianos (UBA) y Centro de Investigaciones Filosóficas. Su más reciente libro es La antinomia de la razón pura en Kant y Hegel (Madrid, 2018). Dirección electrónica: mherszen@gmail.com 
Key words: Nussbaum, Kant, Imagination, Literature, Law

Nuestro sentido de la responsabilidad nace de la imaginación.

Murakami, Kafka en la orilla.

\section{Introducción}

En los últimos años, el estudio literario se ha combinado muy fuertemente con el trabajo teórico iusfilosófico, al punto de volverse casi una sub-especialidad en el área. En este terreno, la obra de Martha Nussbaum, Justicia poética, es de especial importancia por la lucidez y profundidad con la que la autora comprende cómo deben articularse Derecho y literatura en uno de los temas centrales de la filosofía del Derecho: el quehacer judicial. En este sentido, resulta de interés atender a su teoría de la imaginación. En el presente trabajo, me propongo demostrar que la imaginación literaria concebida por Nussbaum viene a resolver un problema central tanto de la filosofía del Derecho y de la actividad judicial, como también un problema clásico de la filosofía teórica, i.e. la articulación entre lo singular y lo universal (en términos jurídicos, este problema se presenta en la articulación entre un caso y una norma). A su vez, sostendré que la teoría de Nussbaum es de raigambre kantiana. Aunque la autora ha ponderado de diversas maneras la filosofía práctica de Kant y ha hecho explícitas referencias a la obra del pensador de Königsberg, lo cierto es que en Justicia poética no hay una mención expresa de la teoría de la imaginación trascendental kantiana. ${ }^{1} \mathrm{~A}$ mi criterio, considerar esta posible filiación iluminará la posición de Nussbaum.

\section{La imaginación literaria, las normas y los hechos}

\footnotetext{
${ }^{1}$ Nussbaum menciona tangencialmente a Kant en lo que refiere al concepto kantiano de dignidad (Nussbaum, Martha, Justicia poética. La imaginación literaria y la vida pública, Santiago de Chile, Editorial Andrés Bello, 1997, p. 18). Volveré sobre este punto más abajo.
} 
En la presente sección, quisiera considerar la teoría de la imaginación literaria de Martha Nussbaum a fin de ponderar su linaje dentro de la tradición filosófica moderna como también sus aportes novedosos a problemas centrales de la filosofía del Derecho y de la tradición filosófica. En este sentido, conviene comenzar con uno de los elementos centrales de la propuesta de Nussbaum: la novela (social) realista. Se trata del género literario característico del siglo XIX, en el que los escritores plasman un medio social real y las tensiones entre éste y los deseos, expectativas y necesidades de un individuo singular. La novela realista reconstruye un contexto social históricamente existente, pero también brinda algo más: permite vivir una vida ajena. ${ }^{2}$

En contraposición a otros géneros literarios (como el cuento, el poema, la biografía, el manual) e incluso a otras disciplinas artísticas (la música, la pintura, la escultura), la novela posee dos notas distintivas que la hacen única: Sólo la novela puede (1) hacernos vivir la vida de otro (en función de su técnica narrativa característica) (2) en el marco de un medio social real. La biografía o el manual de historia nos pueden dar una descripción de los hechos, ponernos en conocimiento (teórico) de lo acontecido, pero no pueden hacernos vivir esos hechos. Por otra parte, el poema, el cuento pueden emocionarnos o compenetrarnos con un hecho puntual. La música, la pintura, la escultura, seguramente son capaces de hablar directamente a nuestras emociones. Pero ninguno de ellos puede reconstruir un medio social en su riqueza y complejidad y hacernos vivir la vida de otro en tal medio. ${ }^{3}$ Nussbaum sintetiza esto en las

${ }^{2}$ Martha Nussbaum, Justicia poética, pp. 31-32, 123. Nussbaum utiliza a lo largo de su libro el término "novela realista" y sólo en la página 123 habla de "novelas sociales realistas". Entiendo que se debe tomar a ambos términos como intercambiables. Es de destacar que siendo la novela realista un tema central de su teoría, la autora apenas mencione tangencialmente a Georg Lukács, de forma anecdótica y sin hacer referencia a la concepción teórica de Lukács sobre la novela o sobre el realismo. Aquí no abordaré el pensamiento de Lukács, pues no me ocupa una teoría de la novela, sino una mirada sobre la función y aptitudes de la imaginación. También cabe señalar que la autora se enfocará exclusiva o casi exclusivamente en la tradición novelista norteamericana, pasando por alto grandes hitos de la novela realista europea.

${ }^{3}$ Ibid., pp. 29-30. 
figuras del lector juicioso, el lector de novelas y el espectador juicioso, figuras que hasta cierto punto se equiparan. ${ }^{4}$

La lectora juiciosa o el lector juicioso son aquellos que pueden cumplir con dos requisitos fundamentales. En primer lugar, leer la novela involucrándose sentimentalmente con el personaje principal. Identificarse con éste, empatizar y, en consecuencia, comprender sus ambiciones, sentimientos, necesidades y expectativas, al punto tal de volverse capaz de sentir como éste sienta y, con ello, comprender el verdadero sentido social y humano de su conducta. ${ }^{5}$ A pesar de empatizar con el personaje principal, el lector juicioso no pierde su objetividad. Este es el segundo requisito: no obstante su empatía, el lector juicioso es capaz de evaluar y ponderar las acciones del personaje principal desde la perspectiva de los valores y normas vigentes en la comunidad. ${ }^{6}$ La comprensión no se convierte en una justificación. Se trata, dice Nussbaum, de una habilidad que se pone en juego, por ejemplo, cuando se juzga la conducta de un ser querido: se empatiza y por ello se comprende mejor, pero no se deja de sopesar su conducta de acuerdo con pautas sociales.

Así, la figura que debe adoptar el juez o la jueza es la del lector juicioso. Por supuesto, aquí no se trata únicamente de que el funcionario judicial sea un habitual lector de novelas y pueda empatizar con personajes ficcionales. Se trata, más bien, de utilizar la imaginación literaria (es decir, esta facultad propia del lector juicioso de novelas) en el expediente judicial: esto es, la imaginación literaria es la facultad de leer la novela o el expediente empatizando con los personajes involucrados y sopesando sus acciones de manera objetiva. Se trata, entonces, de convertir al juez en un lector juicioso.

Esto viene a significar el rechazo por parte de Nussbaum de un esquema simplista de la actividad judicial. El esquema tradicional suele acotar la actividad

\footnotetext{
${ }^{4}$ Nussbaum utiliza los términos lector juicioso, lector de novelas y espectador juicioso. Aunque son términos conceptualmente diferentes, la autora parece equipararlos al menos en lo que hace a los atributos pertinentes para su teoría de la imaginación. Es decir, los rasgos que aquí interesan son compartidos por todos ellos, pues el lector de novela será un lector y espectador juicioso. El rasgo compartido es, precisamente, la imaginación literaria y la empatía imparcial que ella permite. (véase Ibid., p. 112, donde Nussbaum equipara al lector con el espectador).

${ }^{5}$ Ibid., p. 133.

${ }^{6}$ Ibid., pp. 100, 102, 110-112.
} 
judicial a una función cognoscitiva. ${ }^{7}$ Según dicho esquema, esta función consiste, básicamente, en conocer los hechos y el Derecho vigente. Con estos dos elementos, el juez sólo debe subsumir el hecho bajo la norma pertinente y deductivamente llegar a la sentencia. ${ }^{8}$ Este esquema simplista de la actividad judicial podría ser catalogado como pseudocientificismo jurídico ${ }^{9}$, uno de los extremos contra los que la teoría literaria de la justicia de Nussbaum pretende levantarse y sobre el que volveré más adelante.

\footnotetext{
${ }^{7}$ Esta concepción de la tarea judicial se encuentra, según Enrique Marí, vinculada con el desarrollo de los Estados naciones europeos y el proceso de codificación (y debería decirse, sistematización, unificación y simplificación) del Derecho. En este proceso, el surgimiento y entronización de la corriente exegética vino a significar concebir la tarea del juez como una actividad de mero conocimiento y aplicación (subsunción), cfr. Marí, Enrique, "La interpretación de la ley. Análisis histórico de la escuela exegética y su nexo con el proceso codificatorio de la modernidad", en Marí, Enrique, Cárcova, Carlos M., et al., Materiales para una teoría crítica del Derecho, Buenos Aires, Abeledo Perrot, 2006, pp. 177-178, 180-181, 196-197.

${ }^{8}$ Esta posición es la que Cárcova, retomando a Cossio, identifica como intelectualista, y al igual que Marí (véase nota anterior), retrotrae el fundamento de su origen en el surgimiento del temprano capitalismo y en el desplazamiento del antiguo régimen por Estados naciones con un Derecho acorde con las necesidades de la burguesía, cfr. Cárcova, Carlos M., "¿Qué hacen los jueces cuando juzgan? Enfoques pluralistas sobre la interpretación del derecho y la hermenéutica judicial”, en Cárcova, Carlos M., Las teorías jurídicas post positivistas, Abeledo Perrot, Buenos Aires, 2009, pp. 156-157.

${ }^{9}$ Nussbaum no usa este término, pero se refiere en varias oportunidades a enfoques pseudocientíficos. Entiendo que entre estos enfoques pseudocientíficos se debe contar a quienes conciben la actividad judicial como un mero acto de aplicación sistemática y lógica (aplicación o subsunción cuyo carácter científico estaría garantizado por la mera forma silogística). Es en este sentido que la autora dice proponer "una concepción vívida del razonamiento público que sea humanista y no seudocientífica" como un aporte al razonamiento judicial (Martha Nussbaum, Justicia poética, p. 21). Es decir, se trata de la introducción de un elemento que completa la mera subsunción del caso bajo la ley en el quehacer judicial. En igual sentido, sobre la complementación del razonamiento con las emociones, véase Ibid., p. 18.
} 
El elemento central que propone Nussbaum para perfeccionar (ética, política y jurídicamente) ${ }^{10}$ la actividad judicial es la imaginación literaria. La imaginación literaria no es la fantasía desatada. Se trata de la habilidad "lectora" que permite al juez ponerse en el lugar de los involucrados, interpretar sus acciones desde la propia perspectiva de estos, comprendiendo el sentido social de la conducta en el medio social correspondiente y así pudiendo catalogar jurídicamente el hecho de manera idónea.

Es decir que la imaginación literaria nunca procede sola. El juez no utiliza la imaginación y, en consecuencia, se ve librado de todo otro instrumento (jurídico y/o racional). Muy por el contrario, Nussbaum concibe a la imaginación literaria como un instrumento complementario que se suma a la norma y al razonamiento judicial. ${ }^{11}$ Esto implica que el uso de la imaginación no cae en una supresión del Derecho y de la racionalidad, sino se trata de un complemento necesario. Ahora bien, me atrevo a decir que desde la perspectiva de Nussbaum, sin la imaginación literaria estos otros dos elementos son por completo estériles (así como estéril es el pseudocientificismo jurídico antes mencionado). En este sentido, sostendré como hipótesis que la imaginación literaria opera como un instrumento mediador entre la norma y el hecho por juzgar, sin el cual la caracterización jurídica del hecho en cuestión se vuelve azarosa, cuando no caprichosa, injusta o incluso contraria a Derecho, haciendo inútil o ineficaz el razonamiento judicial. En este mismo sentido, sostendré que la imaginación literaria de Nussbaum se encuentra en íntima vinculación con la imaginación trascendental de Kant, con la particularidad de incorporar un elemento emocional (ausente en Kant) que en la propuesta de la autora resulta decisivo. Es sabido que la obra de Martha Nussbaum se encuentra en diálogo y tensión con la del filósofo de Königsberg. ${ }^{12}$ Sin embargo, en este respecto,

${ }^{10}$ Me refiero a un perfeccionamiento ético, político y filosófico de la actividad judicial, ya que Nussbaum señala a éstos como los tres ejes de su propuesta, véase "prefacio" de Justicia poética.

${ }^{11}$ Ibid., pp. 117-118.

12 En Nussbaum, Martha, Las emociones politicas. ¿Por qué el amor es importante para la justicia?, Paidós, Barcelona, 2014, pp. 17-18, la autora afirma que todas las sociedades requieren del uso de emociones para mantener estables sus valores e instituciones. Así, recupera y toma distancia de Kant a la vez, en tanto él reconocía la importancia de incentivar ciertas emociones a través de instituciones religiosas, pero rechazaba que 
no se ha trabajado la relación entre la imaginación literaria y la doctrina de las facultades de Kant, (y en particular con la imaginación trascendental). Propongo pasar entonces a considerar más de cerca a la imaginación literaria para luego establecer su vínculo con las facultades kantianas.

Como he indicado, la propuesta filosófica de Nussbaum de una teoría literaria de la justicia supone un posicionamiento ético, político y jurídico que no se encuentra meramente acotado a un compromiso con la dignidad de la persona en general (aunque tampoco lo rechaza), sino que exige un compromiso con el individuo singular (lo que hace suponer una crítica parcial a la ética kantiana)..$^{13}$ No obstante, considero que aun en esta caracterización de su propuesta filosófica se omite un rasgo. A mi parecer, la imaginación literaria es también un intento de resolver un problema teórico presente en la

esto fuera tarea del Estado. En contraposición a Kant, Nussbaum rescata a Rousseau, para quien el Estado sí debía impulsar una religión civil con carácter coactivo. La autora busca un camino intermedio: pensar cómo un Estado puede influir sobre la faceta emocional de la ciudadanía a fin de provocar efectos políticos en la comunidad, pero sin caer en una posición antiliberal. En Nussbaum, Martha, "Kant and the Stoic Cosmopolitanism", The Journal of Political Philosophy, 5, 1, 1997, pp. 2-4, la autora rescata a Kant de lo que ella identifica como ataques nietzscheanos que rechazarían la intervención de la razón en la política y la vida comunitaria.

13 “([T] odo lo que digo aquí puede concebirse dentro de un kantismo modificado para otorgar a las emociones un papel cognitivo claramente delimitado). Por otra parte, una ética de respeto imparcial por la dignidad humana no logrará comprometer a seres humanos reales a menos que éstos sean capaces de participar imaginativamente en la vida de otros, y de tener emociones relacionadas con esa participación" (Martha Nussbaum, Justicia poética, p. 18). La autora considera que la ética kantiana debe ser complementada con un rol preponderante de las emociones. El mero "respeto imparcial por la dignidad" (que Nussbaum le atribuye a Kant) no conduce a actuar de manera comprometida con un otro concreto. Podría responderse que en Kant los sentimientos (o lo que él llama "corazón") tienen un rol mediador entre las leyes morales puras de la razón y la acción concreta, cfr. Kant, Immanuel, Antropología en sentido pragmático, Losada, Buenos Aires, 2009, parág. 69., y Sánchez Madrid, Nuria, "Resonancias emocionales de la razón en Kant", Princípios: Revista de Filosofia, Natal, v. 23, n. 41, maio-ago, pp. 69-70, para quien el papel del corazón es fundamental en la articulación de la moralidad kantiana. Cfr. también Kant, Immanuel, La religión dentro de los limites de la mera razón, Alianza, Madrid, 1981, p. 56. 
teoría general del Derecho: cómo articular o mediar hechos y normas, o dicho en términos más generales (es decir, en un lenguaje filosófico más general) cómo articular lo singular y lo universal. En el caso que aquí compete, la actividad judicial, se vuelve innegable que teniendo una perspectiva amplia que incluya una mirada dinámica del Derecho -según la terminología de Kelsenesta mediación no puede realizarse por un mero acto de conocimiento y subsunción.

Permítaseme recordar el esquema simplificado (o podría decir simplificador) de cómo articular hechos y Derecho: conociendo el Derecho vigente y el hecho a juzgar, sólo debe aplicarse la norma correspondiente al hecho (o subsumir el hecho bajo la norma) y deductivamente se llega a la sentencia. Como se sabe, el propio Kelsen ya ha rechazado este esquema simplificado, considerando al acto judicial (o más precisamente, a todo acto de aplicación del Derecho por parte de un órgano estatal) como un acto de decisión, de creación, donde el órgano estatal completa según su voluntad el mandato incompleto o indeterminado de la norma superior por aplicar, creando así una norma nueva de jerarquía inferior, y no tratándose de un mero acto de subsunción o aplicación (entendiéndose por ésta una mera tarea de deducción lógica). ${ }^{14}$

Lo cierto es que al introducir una mirada dinámica del Derecho -i.e. una mirada que no se agota en considerar las relaciones (lógicas o semánticas) estáticas entre normas-, se introduce también a los operadores jurídicos que interpretan, aplican las normas, y con esto se vuelve notorio que el hecho no se tipifica solo, que no resulta evidente qué norma ha de aplicársele, etc. Pero no se trata únicamente de una mera cuestión fáctica, el mero hecho de que el Derecho necesita circunstancialmente de humanos que lo apliquen, sino que se trata de una cuestión esencial a la propia noción de Derecho: la invocación de una norma, tachar a una norma de inconstitucional, decretar un acto nulo, etc., se trata siempre de una actividad realizada por un órgano estatal en la que es esencial la interpretación, el pasaje -según el esquema kelseniano- de la norma superior a la norma inferior a través de la actividad de aquellos que por una designación del propio Derecho tendrán a su cargo la jurisdicción. ${ }^{15}$ Es decir, en la propia estructura del Derecho, vista desde la mirada dinámica, se pone en

\footnotetext{
${ }^{14}$ Kelsen, Hans, Teoría pura del derecho, Eudeba, Buenos Aires, 2009, pp. 131, 133.

${ }^{15}$ Uso el término en su sentido etimológico, es decir, como potestad de decir el Derecho, esto es, determinar cuál es el Derecho vigente.
} 
el centro la tarea de la interpretación y creación de normas: es un componente esencial del Derecho moderno la delimitación de los órganos de aplicación (es decir, la designación por parte del propio Derecho de los autorizados a aplicar/interpretar/crear el Derecho). Y a su vez, la validez de esta decisión o acto estatal estará determinada únicamente por la reacción de otros órganos estatales. Es decir, el propio sistema normativo se desarrolla a través de actos humanos y cierra sobre sí mismo el círculo indicando que los propios órganos de creación de Derecho decidirán qué es Derecho y qué no (estando estas designaciones de las autoridades y sus posteriores actos también sujetos a evaluación por parte de ulteriores órganos estatales).

Esto nos lleva a dos reflexiones. Primero, el Derecho no vive fuera de los actos humanos de quienes forman parte de los órganos operadores jurídicos. Insisto en señalar que esto no se debe a una mera deficiencia o circunstancia ocasional que padece el Derecho, como si se dijera: el Derecho es en sí mismo un sistema de normas vinculadas a través de enlaces lógicos y semánticos -podría decir, una entidad ideal o puramente semántica-, pero no queda más remedio que aplicarlo a través de actos humanos (imperfectos). La determinación de la jurisdicción, esto es, la indicación por parte del Derecho de quiénes y cómo deben crear y aplicar el Derecho es necesaria y no circunstancial, es esencial al Derecho y hace a su naturaleza, lo que demanda incorporar a su estudio la perspectiva dinámica. Segundo, no hay forma de contrastar por fuera de estas operaciones de interpretación y aplicación si estas mismas aplicaciones del Derecho son correctas o incorrectas, lícitas o ilícitas, válidas o inválidas. En otras palabras, el sistema Derecho vive únicamente en actos concretos de decisión. Y estos actos de decisión reciben su propia caracterización jurídica (por ejemplo, ser considerados lícitos, ilícitos, nulos, constitucionales, inconstitucionales, etc.) a través de otros actos de decisión llevados a cabo por ulteriores órganos estatales. Estos nuevos actos de decisión serán caracterizados jurídicamente a través de otros eventuales actos de decisión. ${ }^{16}$ El sistema íntegro está (1) cerrado sobre sí mismo (2) en el nivel de

\footnotetext{
${ }^{16}$ Podría decirse que el criterio para calificar una determinada conducta como lícita o ilícita es de carácter coherentista. No se puede conocer la licitud o ilicitud de dicha conducta acudiendo a un elemento externo al mismo quehacer judicial. Esto resulta anti-intuitivo, ya que en general se piensa que la licitud de una conducta se define por una contrastación entre el hecho y la norma, a través de un mero acto de conocimiento.
} 
la eficacia o facticidad, como una víbora que formando un círculo infinito come su propia cola.

Esta última reflexión viene a suponer una crítica a la mirada puramente epistemológica del Derecho que aquí atribuyo al esquema simplificado. El esquema simplificado supone que la aplicación del Derecho a un hecho es una mera tarea de conocimiento, lo que supone que el significado y alcance de una norma son fijos. Lo que a su vez implica que se puede hacer juicios significativos epistemológicamente hablando sobre las aplicaciones del Derecho (por ejemplo, se puede decir con verdad que una norma es inconstitucional, aunque los órganos estatales digan lo contrario, o que la norma 1 no debe ser aplicada al caso 2, a pesar de que los tribunales la apliquen).

Contra este esquema, el propio Kelsen termina reconociendo que no se puede determinar si una norma es válida o no atendiendo únicamente a las relaciones lógicas o semánticas entre normas; como tampoco se puede determinar si un hecho ha sido correctamente tipificado o no estudiando

Luego, el juez podrá ratificar o no esto, lo que permite calificar la conducta del juez como un acierto o un error. Pero lo cierto es que, según los propios criterios del Derecho que se aplica, toda calificación jurídica requiere de una autorización por parte del Derecho mismo. Con lo cual, no hay forma de darle determinada entidad jurídica a una conducta por fuera del hacer de los órganos estatales y, en consecuencia, la tarea judicial es constitutiva (y no declarativa) de dicho carácter jurídico. Esto implica que no se puede predicar error de la tarea judicial (a excepción de un órgano autorizado a eso), ni se puede conocer la calificación jurídica de la conducta antes o por fuera de las tareas de decisión de los múltiples órganos estatales.

En Kennedy se encuentra otro enfoque según el cual la decisión judicial y su caracterización jurídica de un hecho están condicionadas por factores no normativos tales como la habilidad retórica del juez, su aptitud exploratoria del Derecho, el tiempo del que dispone para dedicarle a dicho expediente, las reacciones esperables por parte de la academia y las instancias superiores del poder judicial. Cfr. Kennedy, Duncan, "La educación legal como preparación para la jerarquía", Academia, año 2, n⿳3, enerojunio 2004, pp. 122, 124-126, y Kennedy, Duncan, Libertad y restricción en la decisión judicial: una fenomenología crítica, Universidad de los Andes, Bogotá, 1999, pp. 125, 126, ss., 129. En todo caso, se sigue estando dentro de un enfoque coherentista. 
únicamente el hecho y la norma. ${ }^{17}$ La decisión del juez no es una mera descripción que puede ser verdadera o falsa, es un acto constitutivo del Derecho vigente y de la calificación jurídica de los hechos, acto constitutivo que sólo pierde su vigencia (y por tanto, se podría decir, que su afirmación sobre el status jurídico del hecho en cuestión se vuelve falsa) frente a otro acto de jerarquía superior que lo anule. Esto tiene la paradójica implicancia de que no se puede acceder de forma directa al carácter jurídico de una acción ni a un conocimiento certero del Derecho vigente, i.e. no se puede decir cómo es el Derecho vigente ni si un acto concreto es lícito o ilícito en abstracción de las decisiones judiciales y por fuera de la tradición de interpretación y aplicación del Derecho en cuestión. Todo nuestro conocimiento del Derecho está mediado por las decisiones jurisdiccionales de los órganos estatales, haciendo de éste un conocimiento probabilístico. ${ }^{18}$

Habiendo visto la insuficiencia que plantea el esquema simplificado de la actividad judicial, propongo volver sobre la imaginación literaria en búsqueda

${ }^{17}$ El sentido objetivo, esto es, el sentido jurídico que el sistema normativo atribuye a un hecho, depende en última instancia de la decisión del órgano estatal de aplicación (que es constitutiva de dicho sentido objetivo y no meramente declarativa). Cualquier otra caracterización jurídica del hecho (no realizada por el órgano autorizado) entraría dentro de la tarea académica, interpretación no auténtica, no constitutiva del carácter jurídico del hecho, sino mera descripción de los posibles sentidos de una norma. Lo interesante es que el propio carácter jurídico o antijurídico del acto ejecutado por el órgano estatal reposa a su vez en el accionar de otro órgano estatal.

${ }^{18}$ Cabe aclarar que Kelsen no llega a la conclusión aquí propuesta, sino que se detiene antes y considera el enfoque estático y dinámico como dos miradas sobre un mismo objeto, sin que uno colapse sobre el otro. En mi opinión, la teoría de Kelsen está transida por contradicciones y tensiones (en concordancia con esto, véase Ferrajoli, Luigi, La lógica del derecho. Diez aporías en la obra de Hans Kelsen, Trotta, Madrid, 2017, pp. 90 y ss. y Cárcova, Carlos M., "Notas para una biografía intelectual de Hans Kelsen", en Cárcova, Carlos M., Las teorías jurídicas post positivistas, pp. 87-89. Se trata, desde una perspectiva hegeliana, de las contradicciones internas de una posición filosófica que expresa en dichas contradicciones su insuficiencia y los motivos de su refutación inmanente, así como la necesidad de ser superada en una teoría integradora superior. En este caso, la contradicción consiste en que Kelsen cree que al interior de su teoría pueden convivir pacíficamente el enfoque estático y el enfoque dinámico, que son otra expresión de la contradicción y tensión entre validez y eficacia. El desarrollo de este problema excede este espacio y será tema de otro artículo. 
de auxilio. Es en este sentido que la imaginación literaria viene a incorporarse como un instrumento fundamental a la hora de mediar entre los dos extremos que componen la actividad judicial, el hecho y la norma. La imaginación literaria permite empatizar con los involucrados en el hecho por juzgar y ver la realidad desde sus perspectivas, brindando un campo de sentido social y humano novedoso. El hecho enjuiciado deja de ser una mera secuencia de acciones, el expediente deja de ser una descripción vacía y formal de una conducta exterior. La acción se convierte en el resultado de expectativas, se reviste de sentido por las necesidades del autor, sus deseos y temores. La imaginación literaria, entonces, permite caracterizar más adecuadamente el hecho y, en consecuencia, identificar con más precisión las normas que podrían caracterizarlo.

Para esclarecer el proceder de la imaginación literaria, propongo revisar algunos de los ejemplos que ofrece Martha Nussbaum. La autora ofrece muchos casos dignos de mención. ${ }^{19}$ Aquí consideraré dos: el análisis de las leyes de segregación racial por Herbert Wechsler y el caso "Bowers contra Hardwick". El primero servirá para evaluar cómo (no) determinar la constitucionalidad de una norma (relación entre normas). El segundo servirá para evaluar cómo (no) caracterizar jurídicamente un hecho (relación de una norma con un hecho).

El primer ejemplo se ve en el tratamiento que Wechsler le dispensa a las leyes de segregación racial. ${ }^{20}$ En este caso, Nussbaum se propone mostrar cómo la mirada sobre estas leyes cambia si la persona que lleva a cabo el análisis se pone en el lugar de las personas afectadas por ellas. Wechsler repasa los puntos centrales de las leyes de segregación y toma su lema, "separados pero

${ }^{19}$ Véase por ejemplo los casos literarios plasmados en Native son y Maurice: el primero, un hombre afroamericano juzgado y condenado a pena de prisión en el contexto de la segregación racial; el segundo, un hombre homosexual que debe ocultar su inclinación sexual. En ambos casos, la imaginación literaria que ejerce el lector le permite vivir la vida de estos individuos y padecer cómo su vida se ve afectada por el contexto social adverso. También el caso judicial "Mary J. Carr contra la Allison Gas Turbine Division de la General Motors Corporation" (1994), en el cual se cuenta las situaciones de acoso laboral sufridas por la primera mujer en entrar a trabajar al taller de hojalatería de la empresa mencionada. Es de especial interés confrontar el dictamen del juez de primera instancia con el del tribunal de segunda instancia.

${ }^{20}$ Citado en Martha Nussbaum, Justicia poética, pp. 124 y ss. 
iguales". Frente a este lema, Wechsler se pregunta si la segregación racial (y con ella también otras formas de segregación) sería per se inconstitucional. En dicho análisis, Wechsler sostiene que las normas de segregación serían inconstitucionales por afectar libertades civiles (principalmente, la libertad de asociación), pero -sostiene Wechsler- no por ser discriminatorias en sí mismas. Nótese la llamativa conclusión a la que llega Wechsler. Este razonamiento es de especial interés, pues es un claro ejemplo de cómo la falta de imaginación literaria conduce a obviar los notorios efectos nocivos de una norma y cómo un análisis abstracto (término sobre cuyo sentido volveré) puede llevar a una conclusión contraria a todo sentido común.

Según el razonamiento de Wechsler, las leyes de segregación no son discriminatorias en tanto garanticen iguales condiciones efectivas. Pero lo cierto es que Wechsler pasa por alto por completo el contexto social e histórico de dichas normas, por quiénes son impuestas y con qué objetivos. Wechsler hace un análisis "abstracto", en el sentido de descontextualizar la norma de la realidad humana en la que ésta surge. Wechsler parece olvidar que las leyes y estatutos legales que establecen la segregación en distintas esferas de la sociedad se imponen desde el status quo a ciertos sectores históricamente desventajados, con el objetivo de conservar privilegios, imposibilitar derechos que podrían significar un cambio en las relaciones de poder y dominación en la sociedad, y suponen, en todo caso, la imposición de un estigma sobre un sector de la población.

Considerando el contexto, se ve con claridad el efecto que dichas normas tienen para la persona segregada. Esto es, poniéndonos en su lugar, se puede vivir sus expectativas y deseos, y padecer cómo estos se ven frustrados. Así se advierte que frente a dichas normas el juez debe activar los instrumentos jurídicos destinados a la protección de las minorías. Según Nussbaum, es la imaginación literaria la que revela que las normas son discriminatorias y no la razón o un mero análisis de relaciones entre normas.

El segundo caso es "Bowers contra Hardwick" (Corte Suprema estadounidense, 1986). ${ }^{21}$ La base fáctica del caso es la siguiente: Hardwick es un hombre homosexual acusado de practicar sodomía, actividad sexual castigada por un estatuto penal. Luego de ser acusado y exonerado del delito, Hardwick lleva a cabo una acción judicial para invalidar la ley en cuestión. A

${ }^{21}$ Citado en Ibid., pp. 152 y ss. 
dicha acción judicial se suma una pareja heterosexual, a quien los tribunales le niegan legitimación activa, ${ }^{22}$ porque consideran que no se encontraría en peligro inminente de sufrir un perjuicio directo por el estatuto judicializado. En palabras más simples, los tribunales afirman que la pareja heterosexual no sería alcanzada por dicha norma penal, motivo por el cual se le impide participar de la acción judicial contra la norma en cuestión. Nussbaum señala que esta decisión judicial indica que el Estado pretende aplicar la norma penal exclusivamente sobre la población homosexual. Esto último debería ser indicio suficiente para alertarnos de que el caso requiere echar mano de normas referidas a la protección de minorías. Se trataría claramente de un caso enmarcable dentro de lo que se llama derecho penal de autor ${ }^{23} \mathrm{y}$, en consecuencia, incompatible con un Estado de Derecho. Pero según cuenta Nussbaum, la Corte estadounidense no lo ve así. En su voto, el juez White se propone analizar qué derecho constitucional podría amparar a Hardwick. Para tal fin, pondera los alcances del derecho a la intimidad, pero concluye que según los antecedentes judiciales y doctrinarios, el derecho a la intimidad no abarca la sodomía. Con lo cual, concluye White, la sodomía no tiene protección constitucional.

El primer punto es advertir la redacción del dictamen. Según Nussbaum, la propia redacción de la sentencia da la pauta de la falta de uso de la imaginación literaria. El dictamen es redactado sin prestar atención al sentido social y humano de la conducta que se juzga. Más concretamente, el dictamen

\footnotetext{
${ }^{22}$ Legitimación activa y pasiva se refieren a la aptitud para entablar una acción judicial o ser demandado o querellado. Carecer de legitimación activa significa no poder plantear una acción judicial y esto puede deberse a diferentes motivos. En este caso, se debe a que el órgano judicial entiende que las personas que plantean la acción no se verían afectadas por la norma en cuestión y, por ende, el planteo sería abstracto. Por ejemplo, en nuestro ámbito judicial no tendría legitimación activa para comenzar una demanda de daños una persona que no fuera afectada por el daño sobre el que quiere litigar.

${ }^{23}$ La doctrina diferencia entre Derecho penal de autor y de acto. El Derecho penal de acto se centra en tipificar o caracterizar acciones y castiga, en consecuencia, conductas. El Derecho penal de autor no se centra en las conductas exteriores, sino en modos de ser, características personales. La conducta sólo es relevante como indicio de una nota inmanente a la persona. Sólo el Derecho penal de acto es compatible con un Estado de Derecho.
} 
intenta no pensar a los involucrados como individuos que podrían ser nosotros mismos o nuestros seres queridos. Es decir, el dictamen se aleja de un elemento central de la imaginación literaria: ponderar la situación como si nuestros seres queridos estuvieran involucrados en ella, lo que permitiría sopesar la situación de manera objetiva pero humana. El segundo aspecto por considerar, vinculado con lo anterior, es ponerse en el lugar de la persona implicada y evaluar cuáles son las consecuencias humanas, sociales y emocionales para ella y qué expectativas son frustradas y con qué efectos.

En este caso, nuevamente se ve un tratamiento "abstracto" de la acción y el derecho aplicable a ella. Se toma la acción y se la analiza abstractamente, sin ponderar su sentido humano, sus implicancias sociales y emocionales. En ningún momento White pondera el derecho de tener una pareja, de autodeterminar el modo de vida, de expresar y recibir amor, de perseguir la felicidad. Luego, de esa forma, concluye que el derecho a la intimidad no abarca esta conducta sexual, cuando en realidad -según Nussbaum- no se trata sólo de una determinada práctica sexual, sino de un conjunto de aspectos de la faceta social y emocional de una persona. Esta mirada distante, deshumanizada, es la que le permite a la Corte no advertir los derechos en juego, las normas que brindarían la debida protección. Bien estudiada la cuestión -es decir, según Nussbaum, utilizándose la imaginación literaria-, es evidente que puede aplicarse al caso la protección constitucional del derecho a la intimidad.

Estos dos casos muestran claramente que la imaginación literaria debe intervenir tanto a la hora de analizar las relaciones entre normas como al establecer el sentido jurídico de una conducta o el derecho que la abarca. La imaginación literaria no sólo brinda una mejor comprensión del hecho judicializado -accediendo al sentido social de la conducta-, sino que a través de una mejor comprensión del hecho y del medio social en el que se realiza se puede entender qué norma y qué derechos se ponen en juego en el caso en cuestión y qué elemento normativo debe aplicarse. Se puede advertir que el caso exige prestar atención a normas ideadas para la protección de minorías en contextos sociales hostiles y discriminatorios o se puede advertir si el caso requiere considerar una norma o garantía constitucional especial para la protección de una población especialmente vulnerable. Y sobre todo, nos alejamos de una comprensión absolutamente abstracta, descontextualizada y deshumanizante del Derecho. Con esto quiero decir: toda norma puede pasar el filtro del análisis de constitucionalidad si se la analiza desde una perspectiva 
lo suficientemente abstracta y alejada de la vida humana, dejando de lado sus efectos o el sentido humano de las conductas que ella regula. La imaginación literaria propuesta por Nussbaum, precisamente, atenta contra esta mirada abstracta que logra borrar los efectos de las normas y los sentidos de las conductas, y así hace pasar por alto sus efectos políticos. La imaginación literaria logra recuperar el sentido social y humano de las conductas y las normas, y con ello alcanzar decisiones judiciales más justas y humanas. Y como puede verse, cumple incluso un papel fundamental a la hora de tipificar conductas, esto es, de articular las normas universales y los hechos concretos.

En la siguiente sección se verá cómo la imaginación literaria de Nussbaum puede ser pensada en razón de su parentesco con la doctrina kantiana de las facultades y la tradición filosófica moderna.

\section{La imaginación literaria y la imaginación trascendental de Kant}

De manera análoga a lo que ocurría en la obra de Nussbaum, la imaginación trascendental de Kant juega un papel en la articulación entre lo singular y lo conceptual, entre el caso y la regla. En la Crítica de la razón pura, Kant presenta dos facultades por completo heterogéneas: la sensibilidad y el entendimiento. Mientras la sensibilidad es pasiva, receptiva y se caracteriza por representaciones llamadas intuiciones, el entendimiento es activo, discursivo y se caracteriza por conceptos. ${ }^{24}$ Estas facultades son dos fuentes heterogéneas del conocimiento y precisamente en razón de esta heterogeneidad se requerirá de un elemento mediador, la imaginación.

Así como Kant distingue entre sensibilidad y entendimiento, la propia tradición filosófica ha diferenciado el conocimiento sensible (basado en los sentidos) del intelectual o conceptual (basado en la razón o el entendimiento). ${ }^{25}$ Mientras el conocimiento sensorial brinda conocimiento de lo singular, el conocimiento conceptual brinda un conocimiento de lo general o universal. Sin embargo, aunque Kant reconoce la existencia de estas dos fuentes de

\footnotetext{
${ }^{24}$ Kant, Immanuel, Crítica de la razón pura, Colihue, Buenos Aires, 2007, A15, A19/B33, A68/B93, B150. Todas las citas de la Crítica de la razón pura se indican según el uso académico, indicándose A y B para señalar su primera y segunda edición respectivamente y seguidas de la paginación académica.

25 Véase la nota siguiente.
} 
representaciones, sólo habrá conocimiento según la Crítica de la razón pura cuando ambas estén presentes, es decir, cuando intuición (pura o empírica) y concepto (puro o empírico) se integren o complementen. Un concepto que no sea complementado por una intuición será un concepto vacío, sin objeto. Una intuición sin concepto será una intuición ciega, una representación de nuestros sentidos que resulta inclasificable y, en consecuencia, no es más que una mera sensación subjetiva, una mera alteración de los sentidos sin valor epistemológico objetivo (Kant, Crítica de la razón pura, A50-1/B74-5).

Ahora bien, aunque estas dos facultades deban integrarse para brindar conocimiento (en oposición a lo sostenido, en general, por la tradición empirista y la tradición racionalista $)^{26}$, esto no significa que esta integración sea fácil de explicar. Lo cierto es que la vinculación entre lo singular y lo universal ha sido uno de los grandes problemas en la tradición filosófica y Kant no es la

${ }^{26}$ En general, tanto el empirismo como el racionalismo han pasado por alto la necesidad de integrar el accionar de ambas facultades para la confección del conocimiento teórico. Esto se ha hecho de dos maneras: 1) afirmando la autonomía de ambas facultades (es decir, cada facultad da un conocimiento autónomo); 2) negando la existencia de una de las facultades (Hume, Berkeley y Leibniz). Leibniz cree que entre una representación sensorial y una representación intelectual o conceptual sólo hay una diferencia de grado y no una diferencia de género. Lo que se nos presenta como una representación de los sentidos no es, en verdad, según Leibniz, otra cosa que una representación conceptual confusa. El caso de Spinoza es análogo: la diferencia entre la percepción o la imaginación y el concebir propiamente intelectual se debe a si se conoce un objeto en interacción con nuestro cuerpo o si se conoce al objeto en su relación con el todo de la naturaleza, y no a una variedad de facultades heterogéneas (véase Spinoza, Baruch, Ética, Buenos Aires, Ediciones Orbis, 1982, trad. Vidal Peña, Cap. 5, proposición 29 y su escolio, pp. 353-354). En Hume y Berkeley, se niega la existencia de representaciones universales (tradicionalmente características del entendimiento o la razón). Toda representación es sensorial y singular, y todo conocimiento emerge de la sensibilidad. (Véase Hume, David, Tratado de la naturaleza bumana, libro I, Buenos Aires, Ediciones Orbis, trad. Félix Duque, 1984, pp. 106, 109, 111-112, y Berkeley, George, Principios del conocimiento bumano, Barcelona, RBA, 2002, pp. 35, 38). 
excepción. ${ }^{27}$ Si la intuición brinda un elemento sensorial, singular, dado en espacio y tiempo, rico en determinaciones múltiples, y el concepto brinda, por el contrario, una representación universal o una regla de reconocimiento de la identidad del múltiple otorgado por la sensibilidad, resulta notoria la difícil integración de ambos. El concepto de perro dice mucho menos que las múltiples notas presentadas por un perro singular, dado a la intuición. ¿Cómo el entendimiento advierte que a este objeto singular, concreto, le corresponde el concepto perro y no otro concepto como vaca, gato o mesa? ¿Cómo advierte el entendimiento cuáles son las notas distintivas del objeto a las que debe prestar atención y cuáles son las otras notas sensoriales que puede desatender? Y, además, ¿cómo hace la mente humana para traducir-digamos- el lenguaje de lo sensible al lenguaje de lo conceptual y viceversa? ¿Cómo convierte estas notas sensoriales singulares (por ejemplo, este particular tono de rojo) a un elemento semántico que ya no sea una sensación singular, un dato sensorial concreto, sino una representación que pueda designar todos los casos que contengan tal sensación (o una serie de sensaciones análogas dentro de un margen de variación)?

Como se ve, la articulación entre una instancia singular y un universal es compleja. Aun cuando se trate de la vinculación entre objetos cotidianos y conceptos empíricos, la articulación entre estos dos extremos posee una serie de enigmas difíciles de revelar.

Ahora bien, hasta aquí he considerado ejemplos en los que se articulan instancias singulares empíricas y conceptos empíricos. En realidad, para Kant resulta aún más complicado considerar la articulación entre sensibilidad pura y entendimiento puro. Mientras se trate de conceptos empíricos e intuiciones

${ }^{27}$ Lo que en Kant se presenta como la articulación entre lo conceptual y lo sensorial replica los problemas de la articulación entre lo material y lo abstracto o lo singular y lo universal. Este problema ya se encuentra en la filosofía platónica (quien lo resuelve con el concepto de participación) y en la filosofía aristotélica. En Hegel, viene a formularse en la pregunta por el juicio (aunque no solamente allî). Según Hegel, todo juicio supone articular dos elementos que discrepan y ninguno de los cuales puede reducirse al otro: el sujeto (singular) y el predicado (universal) (y, según Hegel, también al revés, sujeto=universal y predicado=singular). Así, todo juicio afirma un contrasentido, esto es, que lo singular es universal y que lo universal es singular (cf. Hegel, Georg Wilhelm Friedrich, Ciencia de la lógica, t. 2, Buenos Aires, Solar, 1982, pp. 271, 318-322). 
empíricas, lo cierto es que a pesar de su notoria heterogeneidad, ambas representaciones tienen un origen común en la experiencia y se fundan en ella. En el caso de representaciones empíricas, la pregunta es cómo articular una imagen (o caso singular) con un concepto universal empírico. Pero en tanto ambas representaciones son empíricas, surgen y se basan en la experiencia, ya hay un punto de contacto entre ellas que las emparenta y simplifica el problema. Kant resuelve este problema recurriendo a la imaginación como una facultad mediadora, que a través de un procedimiento consistente en trazar en la intuición una figura indeterminada del objeto pensado en el concepto se vuelve capaz de articular los dos extremos que deben relacionarse (lo sensible y lo conceptual, lo singular y lo universal).

Así, la imaginación produce el esquema que es un término medio entre la sensibilidad y el entendimiento. Es el elemento mediador entre estos dos extremos: no brinda en la intuición una imagen concreta para el concepto, pero tampoco se reduce a la regla meramente conceptual o semántica de reconocimiento del objeto. Produce un elemento acorde al concepto (en lo que respecta a su universalidad), pero trazado en la intuición, sensible. A pesar de su carácter sensible, no es singular como una imagen, sino universal, como un procedimiento universal para articular una imagen con su regla, un procedimiento general para trazar en la intuición figuras o imágenes acordes a la regla.

Ahora bien, como he anticipado, para Kant el caso más complejo no es la articulación entre intuiciones empíricas y conceptos empíricos, sino entre conceptos puros del entendimiento (o categorías) y las formas puras de la sensibilidad. En otras palabras, la pregunta que aquí se hace la Crítica de la razón pura es cómo articular sensibilidad y entendimiento, cuando se trata de representaciones puras, es decir, no fundadas en la experiencia.

Kant vuelve a recurrir a la imaginación. En este caso, será la imaginación trascendental y el mediador será el esquema trascendental. A diferencia del esquema empírico, el esquema trascendental es un procedimiento de determinación que no actúa sobre la sensibilidad para crear un esquema general de una determinada clase de objeto. El esquema trascendental es un procedimiento que actúa sobre una de las formas de la sensibilidad, i.e. el tiempo como forma del sentido interno, determinándolo de acuerdo con las categorías puras del 
entendimiento. ${ }^{28}$ De esta manera, se constituye la forma del sentido interno según determinaciones generales concordantes con lo concebido por los conceptos puros del entendimiento, como la unidireccionalidad en el fluir del tiempo, la unidad de todos los momentos del tiempo en un único tiempo, la división del tiempo en unidades homogéneas que toleran ser rellenadas con diferentes cualidades, etc. Es decir, el esquematismo trascendental a cargo de la imaginación trascendental logra articular las dos facultades contrapuestas, la sensibilidad y el entendimiento, permitiendo que las reglas de síntesis puramente conceptuales propias del entendimiento se apliquen a la sensibilidad pura (al tiempo, la forma de todas las intuiciones) y, en consecuencia, a todas las intuiciones.

Como vemos, en la Crítica de la razón pura la imaginación (y particularmente, la imaginación trascendental) es la facultad que cumple la función de mediar entre el caso singular (la intuición) y la instancia universal (el concepto). Ahora bien, quien tiene a su cargo reconocer que un caso debe ser subsumido bajo tal o cual concepto (puro o empírico) es el Juicio o la facultad de juzgar: ${ }^{29}$ Esta facultad es concebida como espontánea. Es quien subsume el caso bajo la regla y quien reconoce al caso como tal. Pero se trata de una facultad incapaz de ser enseñada. Se la tiene o no se la tiene. El jurista o el médico pueden estudiar los conceptos de su disciplina, pero sólo si poseen una facultad de juzgar lo suficientemente aguda serán buenos profesionales en la práctica.

Aunque Nussbaum no remita al papel de la imaginación en la tradición kantiana, pueden advertirse puntos de contacto entre ellos. Aunque también atender a sus diferencias puede resultar pertinente para destacar algunas innovaciones en la teoría de Nussbaum. En este sentido, es interesante la separación kantiana entre imaginación y Juicio, punto sobre el que volveré más adelante. Tanto en Kant como en Nussbaum, la imaginación es quien tiene a su cargo la mediación y articulación entre los extremos: el caso singular y la

\footnotetext{
${ }^{28}$ Aquí sigo la interpretación de Mario Caimi sobre el esquematismo trascendental y la imaginación trascendental. Véase Caimi, Mario, "The logical structure of time according to the chapter on the Schematism", Kant-Studien, Volume 103, Issue 4, 2012, pp. 415-428.

${ }^{29}$ Kant, Crítica de la razón pura, A133-4/B172-3. El término alemán es Urteilskraft. Utilizaré indistintamente "facultad de juzgar" o "Juicio" (en mayúscula para distinguirlo del juicio entendido como entidad lingüística singular).
} 
regla general o concepto. Sin la imaginación, la articulación resulta imposible. En el caso de Kant, las facultades del sujeto cognoscente se mantendrían inconexas e intraducibles las representaciones de cada facultad para la otra. En el caso de Nussbaum, el juez o la jueza puede intentar resolver el caso sin el uso de la imaginación. Pero lo cierto es que este intento cae en un vacío pseudocientifismo formal. Propongo que veamos esto.

Como ya he adelantado, la forma tradicional de concebir el quehacer judicial se centra en dos elementos: la norma y el razonamiento judicial. La norma debe aplicarse al caso singular a través de un mero procedimiento formal de subsunción. Hecho esto, nos encontramos con una consecuencia lógica que hace las veces de sentencia. Invocando la formalidad lógica y el procedimiento deductivo, puede pretenderse que la decisión tomada sea un mero acto de conocimiento, desnudo de todo voluntarismo y, en consecuencia, certero y científico. Pero lo cierto es que en toda decisión judicial interviene la voluntad. La conceptualización de un caso, esto es, elegir qué norma se tomará como premisa mayor del silogismo, requiere un acto de voluntad y un acto de Juicio: atender al caso, advertir cuáles son sus rasgos significativos y elegir una norma acorde. La decisión a través de la cual se conceptualiza el caso, es decir, se lo tipifica, incluye aspectos cognoscitivos, pero también valorativos y volitivos. El ideal cientificista debería brindar un procedimiento exacto sobre cómo tipificar casos, cómo interpretar casos y normas, sin que intervenga la subjetividad, la ponderación personal y la voluntad. Pero lo cierto es que el caso se subsumirá bajo el concepto A o B según a qué rasgo suyo se preste más atención o cuál de sus diversos rasgos parezca esencial o preponderante. ${ }^{30}$

Es decir, la tipificación del caso se asemeja más a una tarea creativa que a una mera actividad cognoscitiva y descriptiva. Y esta tipificación resulta clave para el resultado final del razonamiento judicial. Resultado final del cual Nussbaum no desecha ni la norma ni el razonamiento, sino que exige su

${ }^{30}$ Como señalé más arriba y siguiendo a Kennedy, la tarea de tipificar jurídicamente una conducta está condicionada por numerosos aspectos empíricos que no son estrictamente jurídicos o teóricos: la tradición académica o universitaria, el tiempo de que dispone el juez, su esperanza de encontrar un argumento razonable para fundamentar su sentencia deseada, su conocimiento del Derecho, sus expectativas respecto de la decisión que tomarán las instancias judiciales superiores. 
complemento con la imaginación. Pieza clave que encierra el secreto del buen funcionamiento del razonamiento judicial.

En el caso de Kant, en esta tipificación jurídica de un caso se requeriría la intervención de la imaginación (que articula la mediación entre el caso singular y la regla) y del Juicio. Pero el Juicio posee un carácter enigmático: es actividad espontánea que no puede ser enseñada ni adquirida, tan sólo ejercitada, y no puede aprenderse por medio de una regla. En cambio, Nussbaum parece concebir a la imaginación como una síntesis en la que se integran la imaginación kantiana, la esfera emotiva y el Juicio, con una importante variación: la posibilidad de ser adquirida.

En tanto las emociones para Nussbaum juegan un papel fundamental a la hora de comprender el carácter jurídico del hecho y en tanto ellas pueden ser inculcadas por políticas públicas, debe entenderse que la imaginación literaria no sólo puede ser ejercitada, sino también adquirida. Es decir, a diferencia de lo que ocurre en Kant con el Juicio, no se puede decir según Nussbaum que hay jueces que tienen imaginación literaria y hay jueces que simplemente no la tienen. La actividad de la imaginación literaria parece estar vinculada según Nussbaum a una ejercitación, pero también a un acto de voluntad. El juez de la Corte estadounidense que dicta sentencia en el caso Bowers contra Hardwick decide adoptar una posición alejada de la imaginación literaria, decide redactar su sentencia con un lenguaje lejano y tomando distancia de los implicados.

Lo que la imaginación literaria aporta es una especial comprensión del caso. Una comprensión objetiva en términos de ponderación, pero rica en términos humanos, sociales y emocionales, lo que permite clasificar el caso de una manera más justa y satisfactoria y, en consecuencia, permite identificar mejor las normas que estarían en juego en el caso en cuestión. Su clave es la empatía, la faceta emocional que le permite interpretar el caso desde adentro, desde la vivencia de la vida del otro.

A diferencia de lo que ocurre en Nussbaum, en la imaginación trascendental kantiana la sensibilidad es reducida a su carácter epistemológico, es decir, a la facultad de las representaciones intuitivas. No juega un papel epistemológico la faceta emocional del ser humano. En Nussbaum, por el contrario, lo emocional es clave, aunque esto no autoriza al juez a caer en (1) el sentimentalismo, (2) la parcialidad, (3) ni a dictar sentencia según su compromiso con la agenda pública o (4) con intereses privados. 
Lo cierto es que la faceta emocional es el elemento clave de la mediación y Nussbaum cree que, a diferencia de lo que ocurre con el Juicio en Kant, esta facultad puede ser adquirida. Mientras la vinculación entre el caso y la regla era para Kant el producto de la facultad de juzgar y ésta no podía ser adquirida, Nussbaum exige que el juez o la jueza sean lectores de novela. El juez debe desarrollar la aptitud del lector juicioso; esta aptitud no es un don con el que se nace, sino que es una habilidad que se adquiere y entrena. El juez puede mejorarla con su ejercicio, puede fortalecer su empatía. La apuesta de Nussbaum es, en efecto, que el uso de la imaginación puede evitar la caída en el pseudocientificismo jurídico antes mencionado y en el escepticismo (moral) que caracteriza a la burocracia en razón de su automatización y alienación, y la consecuente deshumanización de las personas involucradas en cada expediente judicial.

\section{Conclusión}

Martha Nussbaum aborda uno de los aspectos centrales de la filosofía del Derecho, el quehacer judicial. Para esto, introduce una idea novedosa, la función de la imaginación literaria en la elaboración de la sentencia. La novedad de la posición de Nussbaum consiste en buscar una nueva forma de articular los extremos de la decisión judicial, esto es, el caso por juzgar y la norma por aplicar, acudiendo a la imaginación. Esta función de la imaginación ya se encuentre presente, de hecho, en la tradición moderna, particularmente en la filosofía kantiana. Es la imaginación trascendental quien tiene a su cargo la articulación entre lo singular-sensorial y lo universal-conceptual. No obstante, la posición de Nussbaum es novedosa, toda vez que concibe a la imaginación literaria de manera diferente a la imaginación trascendental, al introducir en ella la faceta emocional y empática. Como vemos, la propuesta de Nussbaum retoma temas centrales de la tradición filosófica moderna, sobre todo de la filosofía kantiana, y reelaborando una solución de un problema general de la filosofía (el vínculo entre universal y singular) concibe un elemento central para la filosofía del Derecho: la articulación entre norma y hecho a través de la imaginación literaria. 


\section{Referencias bibliográficas}

- Berkeley, George, Principios del conocimiento bumano, Barcelona, RBA, 2002.

- Caimi, Mario, "The logical structure of time according to the chapter on the Schematism”, Kant-Studien, Volume 103, Issue 4, 2012, pp. 415-428.

- Cárcova, Carlos M., “¿Qué hacen los jueces cuando juzgan? Enfoques pluralistas sobre la interpretación del derecho y la hermenéutica judicial”, en Cárcova, Carlos M., Las teorías jurídicas post positivistas, Buenos Aires, Abeledo Perrot, 2009, pp. 155-165.

- Cárcova, Carlos M., "Notas para una biografía intelectual de Hans Kelsen”, en Cárcova, Carlos M., Las teorías jurídicas post positivistas, Buenos Aires, Abeledo Perrot, 2009, pp. 81-91.

- Ferrajoli, Luigi, La lógica del derecho. Diezaporías en la obra de Hans Kelsen, Madrid, Trotta, 2017.

- Hegel, Georg Wilhelm Friedrich, Ciencia de la lógica, t. 1 y 2, Buenos Aires, Solar, 1982.

- Hume, David, Tratado de la naturaleza bumana, trad. Félix Duque, Buenos Aires, Ediciones Orbis, 1984.

- Kant, Immanuel, Antropología en sentido pragmático, Buenos Aires, Losada, 2009.

- Kant, Immanuel, Crítica de la razón pura, trad. Mario Caimi, Buenos Aires, Colihue, 2007.

- Kant, Immanuel, La religión dentro de los límites de la mera razón, Madrid, Alianza, 1981.

- Kelsen, Hans, Teoría pura del derecho, Buenos Aires, Eudeba, 2009.

- Kennedy, Duncan, "La educación legal como preparación para la jerarquía", Academia, año 2, N³, enero-junio 2004, pp. 117-147.

- Kennedy, Duncan, Libertad y restricción en la decisión judicial: una fenomenología crítica, Bogotá, Universidad de los Andes, 1999. 
- Marí, Enrique, "La interpretación de la ley. Análisis histórico de la escuela exegética y su nexo con el proceso codificatorio de la modernidad", en Marí, Enrique, Cárcova, Carlos M., et alii, Materiales para una teoría crítica del Derecho, Buenos Aires, Abeledo-Perrot, 2006, pp. 163-207.

- Nussbaum, Martha, "Kant and the Stoic Cosmopolitanism", The Journal of Political Pbilosophy, 5, 1, 1997, pp. 1-25.

- Nussbaum, Martha, Justicia poética. La imaginación literaria y la vida pública, Santiago de Chile, Editorial Andrés Bello, 1997.

- Nussbaum, Martha, Las emociones políticas. ¿Por qué el amor es importante para la justicia?, Barcelona, Paidós, 2014.

- Sánchez Madrid, Nuria, "Resonancias emocionales de la razón en Kant", Princípios: Revista de Filosofia, Natal, v. 23, n. 41, maio-ago, pp. 33-74.

- Spinoza, Baruch, Ética, trad. Vidal Peña, Buenos Aires, Ediciones Orbis, 1982.

Recibido: 03/2020. Aceptado: 06/2020 